\title{
Structure and Properties of the Neodymium(III) Salts of Poly(ethylene-co-methacrylic acid)
}

\author{
Shoichi Kutsumizu, ${ }^{\dagger}$ Tomomi IKeno, Shunichi Osada, Hisaaki Hara, ${ }^{*}$ \\ Hitoshi TACHINO, ${ }^{*}$ and Shinichi YANO \\ Department of Chemistry, Faculty of Engineering, Gifu University, \\ 1-1 Yanagido, Gifu 501-11, Japan \\ * Technical Center, Du Pont-Mitsui Polychemicals Co., Ltd., \\ 6 Chigusa Kaikan, Ichihara, Chiba 299-01, Japan
}

(Received May 26, 1995)

\begin{abstract}
Neodymium(III) (Nd(III)) salts of poly(ethylene-co-5.4 mol\% methacrylic acid) (EMAA) were synthesized in the neutralization range from 0 to $100 \%$. The coordination structure, the formation and structure of ionic aggregates and their microphase separation were investigated. The infrared spectral results suggested that local environments around Nd(III) ions significantly change near 50\% neutralization. Above this degree of neutralization, the X-ray scattering and visible spectral results indicated the presence of ionic aggregates. Interestingly, almost simultaneously with the ionic aggregation, a microphase separation of ionic aggregates from the polymer matrix (the formation of ionic cluster phase in Eisenberg's terminology) was found to take place by dynamic mechanical and dielectric relaxational measurements. The activation energy for the $\alpha$ relaxation $\left(340-420 \mathrm{~kJ} \mathrm{~mol}^{-1}\right)$, which is attributed to the glass transition of the ionic cluster phase, and the melt flow rate revealed that the $\mathrm{Nd}$ (III) ionomers were densely cross-linked by either isolated or aggregated ions. The stiffness also indicated the existence of the densely cross-links, and the Nd(III) ionomers exhibited the higher stiffness compared with the monovalent and divalent salts of EMAA.

KEY WORDS Ethylene Ionomer / Neodymium Salt / Microphase Separation / Ionic Aggregate / Coordination Structure /
\end{abstract}

Since the pioneer work by Rees et al. ${ }^{1,2}$ in the mid1960's, poly(ethylene-co-methacrylic acid) (EMAA) ionomers have been used for packaging, extrusion coating, and molding applications because of their glass-like high clarity and high modulus superior to those of conventional polyethylene. These ionomer characteristics are known to arise from ionic crosslinking effects by aggregation of ionic groups in the hydrophobic polymer matrix. ${ }^{3-6}$ The structure and properties of ionic aggregates have been extensively studied by many researchers, and several different types of ionomers other than EMAA ionomers have been developed and characterized. Moreover, several morphological models have been proposed to date, ${ }^{5,7-11}$ but the structure of the ionic aggregates and their arrangement in the polymer matrix still remain as an open question.

In general, the nature of neutralizing cation, the degree of neutralization, the flexibility of backbone chains, and the degree of crystallinity of hydrophobic chain segments are important factors in controlling ionic aggregation and designing ionomer properties. In particular, the nature of neutralizing cation such as size, valence, ionicity, or coordination number is a key factor to determine the formation and structure of ionic aggregates. Lefelar and Weiss ${ }^{12}$ proposed a conceptual model based on a crystal closest packing approach, and showed that in carboxylated ionomers such as EMAA ionomers the packing of anionic side groups is determined by the neutralizing cation while in sulfonated ionomers such as sulfonated polystyrene ionomers the anion packing is independent of cations. Experimentally, the effects of cation type on ionic aggregation and the

\footnotetext{
$\dagger$ To whom correspondence should be addressed.
}

relevant properties has been extensively studied using various physical techniques. ${ }^{13-22}$ In ethylene ionomers, Bonotto and Bonner, ${ }^{20}$ and $\mathrm{we}^{21}$ investigated the mechanical properties for several salts of ethylene ionomers and found that the $\mathrm{K}, \mathrm{Na}$, and $\mathrm{Mg}$ salts showed a maximum stiffness near $33 \%$ neutralization while in the $\mathrm{Zn}$ salts, the stiffness initially increased with increasing the neutralization but the increase is saturated at $\sim 80 \%$ neutralization. These degrees of neutralization correspond with each minimal degree of neutralization causing a microphase separation of ionic aggregates from the polymer matrix, which have been found in the mechanical ${ }^{21,23,24}$ and dielectric ${ }^{25-28}$ relaxational studies. Moreover, very recently, we investigated the structure and physical properties of the binary systems of EMAA ionomers neutralized with two types of metal cations, and found that in the $\mathrm{Na} / \mathrm{Zn}$ binary cation system, the stiffness showed a maximum value near $50 \mathrm{~mol} \%$ of $\mathrm{Na}^{22}$ All these studies clearly indicate that the formation and structure of ionic aggregates and the physical properties are closely connected with the strength of ionic interactions and the coordination structure of metal cations. Therefore, cation chemistry is certainly important in designing ionomer properties.

In ethylene ionomers, the structure-property relationships of the trivalent metal salts are unknown, though a wealth of studies has been made on the monovalent and divalent metal salts. Only one paper by $\operatorname{Straus}^{29}$ dealt with the trivalent salts of EMAA, where he chose Al(III) as a trivalent neutralizing cation. Nevertheless, he only obtained the crude Al(III) salts of EMAA because of the synthetic difficulties, which made it impossible to study the structure and physical properties of these materials. On the other hand, a few reports have been published 
on the rare-earth(III) salts of poly(ethylene-co-acrylic acid) (EAA) by Li et al., ${ }^{30,31}$ but the neutralization level was under $20 \%$, because their interest was focused on the catalytic activity in butadiene polymerization and not the ionomer properties. From these points of view, the structure and physical properties of EMAA ionomers neutralized with trivalent metal cations are interesting.

In this work, we choose rare-earth(III) ions as a trivalent neutralizing cation, and we succeed in synthesizing the neodymium(III) (Nd(III)) salts of EMAA with various degrees of neutralization up to $100 \%$ by use of the melt reaction process. ${ }^{33}$ This melt reaction method $^{21,32,34}$ has been found to be very useful to obtain various salts of EMAA ionomers thoroughly purified (e.g., free from organic solvents that often influence the structure and properties of ionomers ${ }^{35}$ ). The purpose of this work is to clarify the structure and physical properties of the $\mathrm{Nd}$ (III) salts of EMAA. The coordination structure, the formation of ionic aggregates and the microphase separation, and the relevant physical properties were investigated from X-ray scattering, visible and infrared (FT-IR) spectroscopic, differential scanning calorimetric (DSC), dilatometric, dynamic mechanical and dielectric relaxational, and melt viscosity (melt flow rate) studies.

\section{EXPERIMENTAL}

\section{Preparation of the Nd(III) Salts of EMAA}

The starting EMAA polymer was a random ethylene copolymer made by Du Pont-Mitsui Polychemicals Co., Ltd., whose MAA content was $5.4 \mathrm{~mol} \%$. Neutralization of EMAA by $\mathrm{Nd}(\mathrm{III})$ was accomplished by a melt reaction of EMAA and $\left(\mathrm{CH}_{3} \mathrm{COO}\right)_{3} \mathrm{Nd}(\mathrm{III}) \cdot 3 \mathrm{H}_{2} \mathrm{O}$ at $453-473 \mathrm{~K}$ for $30-45 \mathrm{~min}$ using a Brabender PLE 651 plasti-corder with a rotor turning of $40 \mathrm{rev} \mathrm{min}^{-1}$. During the reaction, the mixing bowl was degassed by a rotary pump to maintain the reduced atmosphere of $250-600 \mathrm{mmHg}$. The products obtained were compression-molded into 0.5 -mm-thick sheets at $423 \mathrm{~K}$ and were dried under a reduced pressure of $5-10 \mathrm{mmHg}$ at $413 \mathrm{~K}$ for 1 hour to remove residual water and acetic acid; the vacuum-drying frequently altered the IR spectral pattern, and so, this procedure was repeated (usually 2 or 3 times) until no alteration was observed in the spectral pattern. Elemental analyses were performed in the Laboratory for Organic Elemental Microanalysis of Kyoto University, and the results indicate that the neutralization reaction proceeded stoichiometrically, as shown in Table I. The $\mathrm{Nd}(\mathrm{III})$ ionomers are hereafter denoted as EMAA- $x \mathrm{Nd}$, where $x(0 \leq x \leq 1)$ is the degree of neutralization by $\mathrm{Nd}(\mathrm{III})$. As reported previously, ${ }^{36,37}$ a small amount $(0.5-3 \mathrm{wt} \%)$ of water uptake profoundly, in general, changes the structure and physical properties of EMAA ionomers. The dry samples were stored at room temperature in a vacuum dessicator before use, but absorbed a very small amount of water within the level of residual water as seen in Table I, where the amount of absorbed water was determined from the weight loss by vacuum-drying at about $413 \mathrm{~K}$ for 1 hour, and these data are also included.
Table I. Elemental analysis data of EMAA $-x \mathrm{Nd}$

\begin{tabular}{|c|c|c|c|c|c|}
\hline \multirow{3}{*}{ Sample } & \multicolumn{2}{|c|}{$\mathrm{C} \%$} & \multicolumn{2}{|c|}{$\mathrm{H} \%$} & \multirow{2}{*}{$\begin{array}{c}\text { Residual } \\
\text { water }\end{array}$} \\
\hline & Clacd & Found & Calcd & Found & \\
\hline & $\%$ & $\%$ & $\%$ & $\%$ & $\%$ \\
\hline EMAA & 81.2 & 80.7 & 13.3 & 13.4 & 0.10 \\
\hline EMAA $-0.1 \mathrm{Nd}$ & 80.5 & 79.9 & 13.2 & 13.6 & \\
\hline EMAA $-0.2 \mathrm{Nd}$ & 79.9 & 79.3 & 13.0 & 13.3 & 0.08 \\
\hline EMAA $-0.3 \mathrm{Nd}$ & 79.3 & 78.9 & 12.9 & 12.3 & \\
\hline EMAA $-0.4 \mathrm{Nd}$ & 78.6 & 78.0 & 12.8 & 12.8 & $<0.01$ \\
\hline EMAA $-0.5 \mathrm{Nd}$ & 78.0 & 77.2 & 12.7 & 12.8 & \\
\hline EMAA $-0.6 \mathrm{Nd}$ & 77.4 & 77.3 & 12.6 & 12.6 & 0.12 \\
\hline EMAA- $-0.8 \mathrm{Nd}$ & 76.2 & 75.7 & 12.3 & 12.5 & 0.27 \\
\hline EMAA-1.0Nd & 75.1 & 74.3 & 12.1 & 12.2 & \\
\hline
\end{tabular}

\section{Physical Measurements}

$\mathrm{X}$-Ray scattering measurements were performed with a Mac Science $\mathrm{X}$-ray generator $\left(\mathrm{MXP}^{3}\right.$ system) operated with a copper target at a $50-\mathrm{kV}$ accelerating potential and $40-\mathrm{mA}$ emmision current. The $\mathrm{Cu}-K_{\alpha}$ radiation $(\lambda=1.54050 \AA)$ was selected with a graphite monochromator. The divergence and scattering slits were $1^{\circ}$, and the receiving slit was $0.15 \mathrm{~mm}$. Samples were scanned at $2.0^{\circ} \mathrm{min}^{-1}$ at room temperature.

Visible spectra were measured using a Hitachi 330 or a Shimadzu UV-2100 PCS recording spectrophotometer at room temperature. The thickness of the samples used were $0.2-0.5 \mathrm{~mm}$.

IR spectra were measured for $c a .50 \mu \mathrm{m}$-thick films with a Perkin Elmer 1640 FT-IR spectrometer at room temperature, where 64 scans at a resolution of $4 \mathrm{~cm}^{-1}$ were signal averaged.

DSC measurements were carried out with a Seiko Denshi DSC-210 differential scanning calorimeter (SSC5000 system) at a heating/cooling rate of $10 \mathrm{~K} \mathrm{~min}^{-1}$ under a dry $\mathrm{N}_{2}$ flow of $c a .40 \mathrm{~mL} \mathrm{~min}^{-1}$. The instrument was calibrated by indium $\left(\mathrm{mp} 156.6^{\circ} \mathrm{C}, \Delta H=28.458\right.$ $\left.\mathrm{cal} \mathrm{g}^{-1}\right)$ and tin $\left(\mathrm{mp} 231.9^{\circ} \mathrm{C}, \Delta H=59.5 \mathrm{calg}^{-1}\right)$. ca. $10 \mathrm{mg}$ of the samples weighed to $10^{-2} \mathrm{mg}$ were heated to $433 \mathrm{~K}$ and then cooled to room temperature at a rate of $10 \mathrm{~K} \mathrm{~min}^{-1}$. After this, the samples were stored at room temperature for 30 days in a vacuum dessicator until used. The temperature $\left(T_{\mathrm{i}}\right)$ of the order-disorder transition of ionic aggregate regions ${ }^{38-40}$ and its enthalpy change $\left(\Delta H_{\mathrm{i}}\right)$ and melting point $\left(T_{\mathrm{m}}\right)$ and crystallization temperature $\left(T_{\mathrm{c}}\right)$ of polyethylene crystallites and their enthalpy changes $\left(\Delta H_{\mathrm{m}}\right.$ and $\left.\Delta H_{\mathrm{c}}\right)$ were obtained from the DSC data. The weight fraction of crystallinity $\left(X_{\mathrm{c}}\right)$ was calculated from the value of $\Delta H_{\mathrm{c}}$ by assuming that the heat of fusion of polyethylene crystallites is $290.4 \mathrm{~J} \mathrm{~g}^{-1}$.

Thermal expansions were measured at a heating/cooling rate of $c a .0 .5 \mathrm{~K} \mathrm{~min}^{-1}$ using a glass capillary dilatometer (0.6-mm i.d.). A compression-molded sheet of $\sim 1 \mathrm{~g}$ was aged at room temperature for more than 1 month, and then carefully immersed in liquid mercury in vacuo to avoid the formation of voids on the surface of the sheet. The volume change of the sample with temperature was calculated from a reading of the height of mercury in the capillary of the dilatometer. The density at $298 \mathrm{~K}$ was obtained by a buoyancy method with benzene. 
Dynamic mechanical properties were measured using a Rheospectoler Model DVE-V4 (Rheology Co., Ltd.) attached to a NEC PC9801EX computer. A compression-molded sheet was cut into a specimen of approximately $20-\mathrm{mm}$ length, $6-\mathrm{mm}$ width, and $2-\mathrm{mm}$ thickness, and then aged at room temperature for 30-40 days before the measurements. The tensile mode was analyzed under a constant tension, at a heating rate of $3 \mathrm{~K} \mathrm{~min}^{-1}$ in the temperature range from 123 to $393 \mathrm{~K}$ and at frequencies of 1,10 , and $100 \mathrm{~Hz}$.

Dielectric measurements were carried out with a multifrequency LCR meter (Yokogawa-Hewlett Packard, type 4274A) attached to a NEC PC9801F2 computer, by use of the three terminal electrode system described previously ${ }^{41}$; the outer diameter of the guarded electrode was $37 \mathrm{~mm}$, and those of the unguarded electrode and the guard electrode were $50 \mathrm{~mm}$, while the inner diameter of the guard electrode was $39 \mathrm{~mm}$. The specimens for dielectrcic measurements were circular sheets of $50-\mathrm{mm}$ diameter and about $0.5-\mathrm{mm}$ thickness. To ensure electrical contact between the electrode and specimen, gold was carefully deposited in vacuo on the surface of the specimen, and then the specimen was aged at room temperature for 30-50 days. The measurements were made under $\mathrm{N}_{2}$ atmosphere in the temperature from 90 to $400 \mathrm{~K}$ and at several frequencies between $100 \mathrm{~Hz}$ and $100 \mathrm{kHz}$. The temperature was measured by a calibrated Fe-constantan thermocouple touched with the guard electrode.

The melt flow rate (MFR) was measured as the weight of polymer flow $(\mathrm{g} / 10 \mathrm{~min})$ from a melt indexer at $463 \mathrm{~K}$ under a 2160 -g load.

Stiffness was measured at room temperature using a Toyoseiki stiffness tester according to ASTM D-747. The specimens of $100-\mathrm{mm}$ length and $20-\mathrm{mm}$ width were stamped out from a 3-mm thick compressionmolded sheet and aged at $296 \mathrm{~K}$ for 2 months before the measurements.

Tensile properties were tested using an Intesco Model 201 at room temperature and with a crosshead speed of $200 \mathrm{~mm} \mathrm{~min}^{-1}$. The specimens, stamped out from a $2-\mathrm{mm}$ thick compression-molded sheet, were in the shape of a dogbone according to JIS K-6760 and aged at $296 \mathrm{~K}$ for a few days before the measurements.

\section{RESULTS AND DISCUSSION}

\section{$X$-Ray Scattering}

Figure 1 shows X-ray scattering patterns of EMAA$x \mathrm{Nd}$. When the degree of neutralization $(x)$ is 0.5 or less, two peaks near $2 \theta=21$ and $23^{\circ}$ ( $2 \theta$ is the scattering angle) are clearly visible, riding on a broad amorphous halo near $19^{\circ}$. The 21 and $23^{\circ}$ peaks are assigned to the (110) and (200) diffractions from the polyethylene crystalline region, respectively. Their intensities decrease with increasing $x$ and almost disappear at $x=0.6$. These results are well consistent with the DSC results which will be presented later in Figure 8. At $x \geq 0.4$, another peak appears near $2 \theta=5^{\circ}$. This result indicates that ionic aggregation occurs at $x \geq 0.4$ because the $5^{\circ}$ peak is assigned to a so-called ionomer peak. The Bragg spacings $\left(d_{\text {Bragg }}\right)$ of the ionomer peak in the $\mathrm{Nd}(\mathrm{III})$ ionomers are $17-20 \AA$, being almost equal to those in

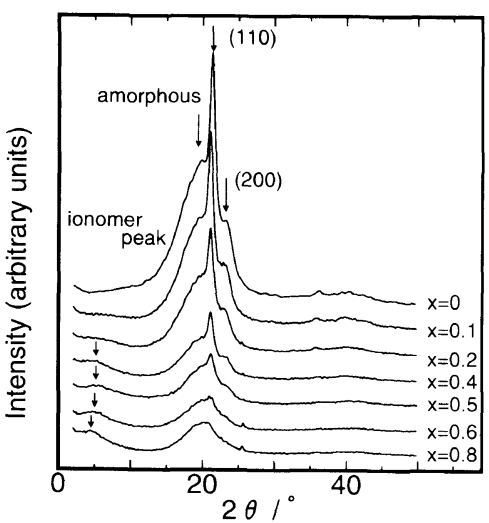

Figure 1. X-Ray scattering patterns of EMAA- $x \mathrm{Nd}$.

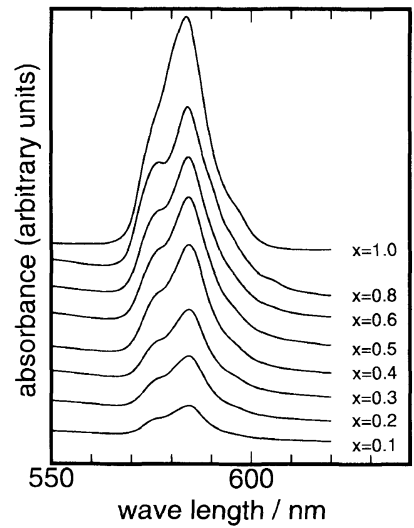

Figure 2. Visible spactra in the region of $550-620 \mathrm{~nm}$ for EMAA $x \mathrm{Nd}$.

the $\mathrm{Zn}$ (II) ionomers ${ }^{42,43}\left(d_{\mathrm{Bragg}}=17-19 \AA\right)$ but slightly smaller than those in the $\mathrm{Na}$ ionomers ${ }^{3,43}\left(d_{\mathrm{Bragg}}=\right.$ $19-27 \AA$ ). Assuming that the $d_{\text {Bragg }}$ value roughly corresponds to the inter-aggregate distance and that all the neutralized side groups are incorporated into ionic aggregates, ${ }^{44}$ the larger $d_{\text {Bragg }}$ means the larger size of ionic aggregates, and hence, it is concluded that the size of ionic aggregates in the $\mathrm{Nd}$ (III) ionomers is almost equal to that in the $\mathrm{Zn}$ (II) ionomers but smaller than that in the $\mathrm{Na}$ ionomers.

\section{Visible Spectra}

Figure 2 shows visible spectra in the region of 550 $620 \mathrm{~nm}$ for EMAA $-x \mathrm{Nd}$. All the samples exhibit a broad absorption band near $585 \mathrm{~nm}$, which is assigned to the $\mathrm{Nd}$ (III) ${ }^{4} \mathrm{I}_{9 / 2} \rightarrow{ }^{4} \mathrm{G}_{5 / 2},{ }^{4} \mathrm{G}_{7 / 2}$ transition. According to Karraker, ${ }^{45}$ the band shape of this transition is sensitive to the coordination number and ligand geometry on Nd(III) ions. The band shapes observed for all the EMAA $-x \mathrm{Nd}$ samples are fairly similar to that for the 8 -coordinated $\mathrm{Nd}$ (III) ion in $\mathrm{Nd}\left(\mathrm{CF}_{3} \mathrm{COCHCOCF}_{3}\right)_{4} \cdot{ }^{45}$ Therefore, we concluded that the averaged coordination number of $\mathrm{Nd}(\mathrm{III})$ ions is 8 in EMAA $-x \mathrm{Nd}$, independent of $x$.

Figure 3 shows plots of the peak absorbance of $\mathrm{Nd}$ (III) ${ }^{4} \mathrm{I}_{9 / 2} \rightarrow{ }^{4} \mathrm{G}_{5 / 2},{ }^{4} \mathrm{G}_{7 / 2}$ band versus $x$ in EMAA $-x \mathrm{Nd}$, where the peak absorbance is normalized to the same thickness of $1 \mathrm{~mm}$. The plots appear to be composed of two straight lines and the slope above $x=0.5$ is about onefourth of that below $x=0.5$. The deviation of Beer's 


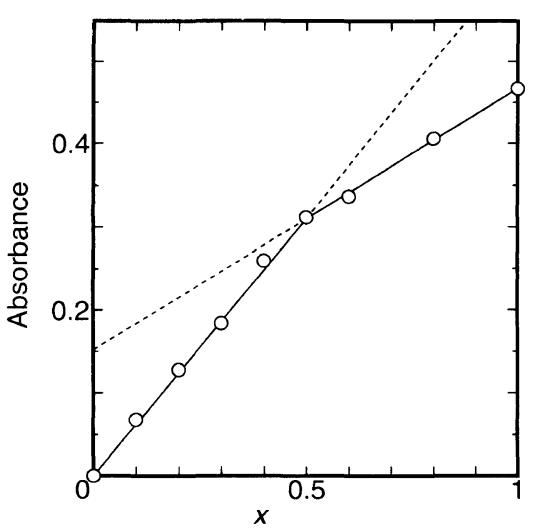

Figure 3. Plots of the peak absorbance of the $\mathrm{Nd}(\mathrm{III}){ }^{4} \mathrm{I}_{9 / 2} \rightarrow{ }^{4} \mathrm{G}_{5 / 2}$, ${ }^{4} \mathrm{G}_{7 / 2}$ band versus the degree of neutralization $(x)$. Linear least-squares fits are also shown as solid lines.

law above $x=0.5$ indicates the existence of $\mathrm{Nd}(\mathrm{III})$ $\mathrm{Nd}$ (III) interactions above $x=0.5$, and, in other words, that the local environment of $\mathrm{Nd}(\mathrm{III})$ ions changes around $x=0.5$ with increasing $x$. These results support the X-ray scattering results that ionic aggregation occurs at $x>0.4$ (see Figure 1).

\section{IR Spectra}

Figure 4 shows IR spectra in the region of $1100-$ $1800 \mathrm{~cm}^{-1}$ for EMAA- $x$ Nd. Spectral intensities are normalized by the intensity of the $\mathrm{CH}_{2}$ bending peak at $1467 \mathrm{~cm}^{-1}$, where it is assumed that the intensity of the $1467-\mathrm{cm}^{-1}$ band is unchanged with $x .^{46}$ In this figure, two peaks near 1698 and $1270 \mathrm{~cm}^{-1}$ are assigned to hydrogen-bonded carbonyl stretchig bands $v(\mathrm{C}=\mathrm{O})$ and $v(\mathrm{C}-\mathrm{O})$, respectively, and two peaks in the region of $1600-1500 \mathrm{~cm}^{-1}$ and at $1406 \mathrm{~cm}^{-1}$ are assigned to the asymmetric $\left(v_{\mathrm{as}}\left(\mathrm{COO}^{-}\right)\right)$and symmetric $\left(v_{\mathrm{s}}\left(\mathrm{COO}^{-}\right)\right)$ carboxylate stretching bands, respectively. ${ }^{2,30,31}$ The intensities of these peaks depend on $x$, but their frequencies are almost independent of $x$. As $x$ increases, the intensity of the $1698-\mathrm{cm}^{-1}$ band decreases and then another new peak appears near $1669 \mathrm{~cm}^{-1}$. Figure 5 plots the intensities of the 1698 - and $1669-\mathrm{cm}^{-1}$ bands and the sum of these two intensities against $x$. The intensity of the $1698-\mathrm{cm}^{-1}$ band monotonously decreases as $x$ increases from 0 to 1.0 . On the other hand, the intensity of the $1669-\mathrm{cm}^{-1}$ band increases when $x$ increases from 0 to 0.5 , but begins to decrease above $x=0.5$. Since the sum of these two intensities gives a straight line with zero at $x=1.0$, it can be considered that the $1669-\mathrm{cm}^{-1}$ band is also associated with the unneutralized $\mathrm{COOH}$ groups. Han and Williams ${ }^{46}$ reported that $v(\mathrm{C}=\mathrm{O})$ bands in several metal salts of EMAA shift to lower frequencies with increasing $x$ and suggested that this is due to the formation of acid-base complexes between metal cations (acting as a Lewis acid) and unneutralized $\mathrm{COOH}$ groups. Therefore, we assigned the $1669-\mathrm{cm}^{-1}$ band to the stretching vibration of hydrogen-bonded carbonyl groups that are weakly coordinated to the $\mathrm{Nd}(\mathrm{III})$ carboxylates.

In the region of $1500-1600 \mathrm{~cm}^{-1}$, three $\mathrm{COO}^{-}$ asymmetric stretching bands $\left(v_{\text {as }}\left(\mathrm{COO}^{-}\right)\right)$are observed at $1584,1541,1518 \mathrm{~cm}^{-1}$, suggesting that the $\mathrm{COO}^{-}$ groups in EMAA $-x \mathrm{Nd}$ are at least in three different

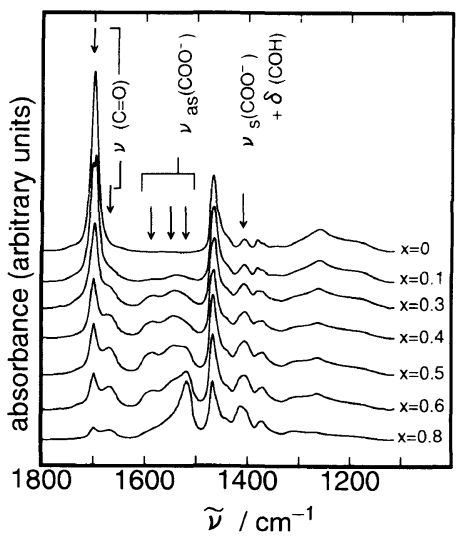

Figure 4. IR spectra in the region of $1100-1800 \mathrm{~cm}^{-1}$ for EMAA$x \mathrm{Nd}$.

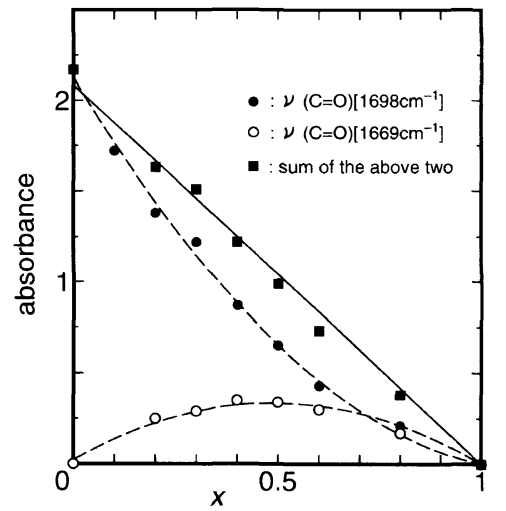

Figure 5. Plots of the peak absorbances of the 1698- and $1669-\mathrm{cm}^{-1}$ bands and the sum of these two bands versus $x$. First- and second-order polynomial fits are also shown as solid and dashed lines, respectively.

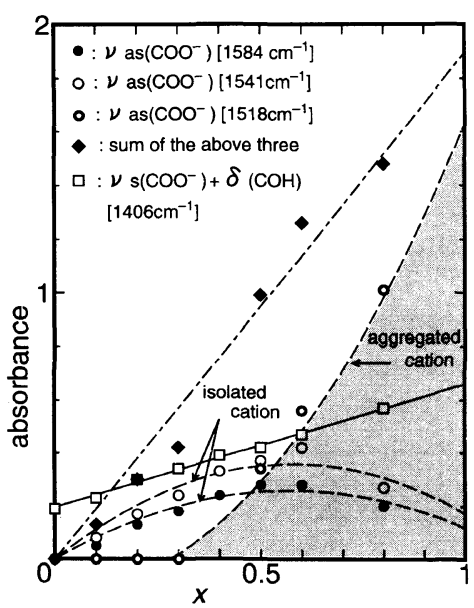

Figure 6. Neutralization $(x)$ dependence of the peak intensities of

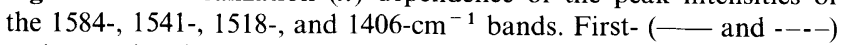
and second-order (---) polynomial fits are also shown.

environments. Figure 6 shows neutralization dependence of the intensities for these three bands, along with the data for the $\mathrm{COO}^{-}$symmetric stretching band $\left(v_{\mathrm{s}}\left(\mathrm{COO}^{-}\right)\right)$ at $1406 \mathrm{~cm}^{-1}$. The $v_{\mathrm{s}}\left(\mathrm{COO}^{-}\right)$band is superposed on the $\mathrm{C}-\mathrm{O}-\mathrm{H}$ in-plane bending band $(\delta(\mathrm{COH}))$ at $1407 \mathrm{~cm}^{-1}$, but the intensity of the latter band is considered to be almost independent of $x$. In the range $x=0-0.4$, only two $v_{\mathrm{as}}\left(\mathrm{COO}^{-}\right)$bands at 1584 and $1541 \mathrm{~cm}^{-1}$ are present (see also Figure 4), and their intensities increase with increasing $x$. Above $x=0.5$, the band at $1518 \mathrm{~cm}^{-1}$ 
appears, and its intensity steeply increases with increasing $x$, while the intensities of the $1584-$ and $1541-\mathrm{cm}^{-1}$ bands gradually decrease. The sum of the intensities of these three bands increases in proportion to $x$ and this relation seems to hold for $v_{\mathrm{s}}\left(\mathrm{COO}^{-}\right)$band. Nakamoto ${ }^{4}$ argued that the higher symmetry of $\mathrm{COO}^{-}$groups on the coordination to metal ions may give the smaller difference between $v_{\text {as }}\left(\mathrm{COO}^{-}\right)$and $v_{\mathrm{s}}\left(\mathrm{COO}^{-}\right)$frequencies. Since the frequency difference in EMAA $-x \mathrm{Nd}$ decreases from 133 to $106 \mathrm{~cm}^{-1}$ with increasing $x$ from 0.1 to 0.8 , the average mode of coordination of the $\mathrm{COO}^{-}$gruops is considered to become more spherically symmetric. The frequencies of the $1584-$ and $1541-\mathrm{cm}^{-1}$ bands almost agree with those of $\mathrm{Nd}(\mathrm{III})$ acetates ${ }^{45}$ $\left(v_{\text {as }}\left(\mathrm{COO}^{-}\right)=1550-1535 \mathrm{~cm}^{-1}\right)$, and therefore, these two bands are associated with isolated Nd(III) carboxylates. The $1518-\mathrm{cm}^{-1}$ band, which is present only in highly neutralized EMAA $-x \mathrm{Nd}$, is probably associated with aggregated $\mathrm{Nd}(\mathrm{III})$ carboxylates. From these assignments, we can depict the following picture: From the law of electric neutrality, three $\mathrm{COO}^{-}$groups coordinate to one $\mathrm{Nd}(\mathrm{III})$ ion. The 8-coordination, which was deduced by the visible spectra, should require another two oxygens, assuming that the $\mathrm{COO}^{-}$groups act as a bidentate ligand. Such oxygens can be offered from the carbonyl groups of unneutralized $\mathrm{COOH}$ groups exhibiting the $1669-\mathrm{cm}^{-1} v(\mathrm{C}=\mathrm{O})$ band. As mentioned above, ionic aggregation takes place above $x=0.5$, and in ionic aggregate regions, one oxygen of $\mathrm{COO}^{-}$groups may be shared with two adjacent $\mathrm{Nd}$ (III) ions, giving rise to corner-sharing, edge-sharing, or face-sharing of two $\mathrm{NdO}_{8}$ octahedra. This would lower the electron density of $\mathrm{O}==\mathrm{C}==\mathrm{O}^{-}$bond and hence lower the frequency of the $v_{\mathrm{as}}\left(\mathrm{COO}^{-}\right)$band, resulting in the appearance of the $1518-\mathrm{cm}^{-1}$ band. Such sharings, on the other hand, would reduce the number of $\mathrm{COOH}$ carbonyl groups required to the 8-coordination, resulting in the decrease of the intensity of the $1669-\mathrm{cm}^{-1}$ $v(\mathrm{C}=\mathrm{O})$ band, as observed. It is concluded that the local environment of the $\mathrm{Nd}(\mathrm{III})$ ions substantially changes near $x=0.5$, and this change reflects the formation of ionic aggregates, indicated by the X-ray scattering results mentioned above.

\section{DSC Data}

Figure 7 shows DSC curves for EMAA-0.6Nd aged at room temperature for 30 days. In the first heating, EMAA-0.6Nd exhibits two endothermic peaks near 324 and $359 \mathrm{~K}$. Clearly, the $359-\mathrm{K}$ peak originates from the melting of the polyethylene crystalline regions $\left(T_{\mathrm{m}}\right)$. The subsequent cooling shows an exothermic peak at $321 \mathrm{~K}$, which is assigned to the recrystallization of polyethylene segments $\left(T_{\mathrm{c}}\right)$. In the second heating, only the $T_{\mathrm{m}}$ peak is seen near $358 \mathrm{~K}$, and the lower temperature peak $\left(T_{\mathrm{i}}\right)$ disappears. The $T_{\mathrm{i}}$ peak reappeared by aging at room temperature after the second heating. The DSC curves for other $\mathrm{EMAA}-x \mathrm{Nd}$ ionomers were essentially the same as those for EMAA-0.6Nd described above, and the thermal parameters obtained for all the $\mathrm{Nd}$ (III) ionomers are summarized in Table II. Although the thermal hysteresis found on DSC is a general feature of EMAA ionomers, a final answer has not been obtained yet for the assigment of $T_{\mathrm{i}}$ peak. On the basis of our

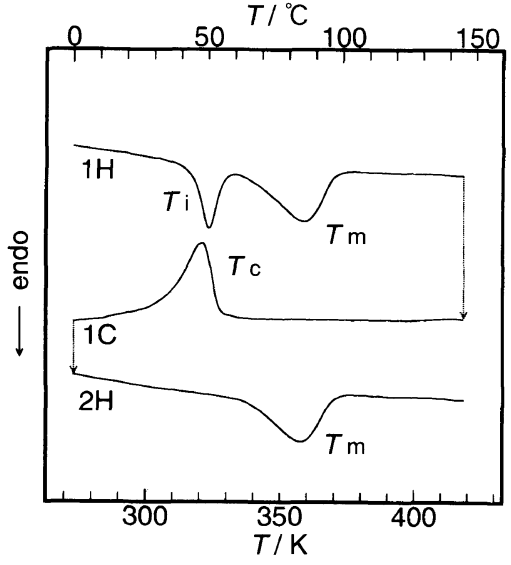

Figure 7. DSC curves for EMAA-0.6Nd: $1 \mathrm{H}$, 1st heating; 1C, 1st cooling; $2 \mathrm{H}, 2$ nd heating.

Table II. DSC parameters of EMAA $-x \mathrm{Nd}$

\begin{tabular}{|c|c|c|c|c|c|c|c|c|}
\hline \multirow{3}{*}{ Sample } & \multicolumn{4}{|c|}{$\begin{array}{c}\text { 1st } \\
\text { heating }\end{array}$} & \multicolumn{2}{|c|}{$\begin{array}{c}1 \text { st } \\
\text { cooling }\end{array}$} & \multicolumn{2}{|c|}{$\begin{array}{c}2 \text { nd } \\
\text { heating }\end{array}$} \\
\hline & $T_{\mathrm{i}}$ & $\Delta H_{\mathrm{i}}$ & $T_{\mathrm{m}}$ & $\Delta H_{\mathrm{m}}$ & $T_{\mathrm{c}}$ & $\Delta H_{\mathrm{c}}$ & $T_{\mathrm{m}}$ & $\Delta H_{\mathrm{m}}$ \\
\hline & K & $\mathrm{J} \mathrm{g}^{-1}$ & $\mathrm{~K}$ & $\mathrm{Jg}^{-1}$ & $\mathrm{~K}$ & $\mathrm{Jg}^{-1}$ & K & $\mathrm{Jg}^{-1}$ \\
\hline EMAA & 324 & 8 & 364 & 62 & 332 & 71 & 364 & 64 \\
\hline EMAA- $-0.1 \mathrm{Nd}$ & 315 & 9 & 363 & 63 & 344 & 69 & 362 & 64 \\
\hline EMAA $-0.2 \mathrm{Nd}$ & 318 & 10 & 363 & 59 & 342 & 66 & 362 & 59 \\
\hline EMAA $-0.3 \mathrm{Nd}$ & 319 & 11 & 362 & 53 & 338 & 62 & 363 & 53 \\
\hline EMAA $-0.4 \mathrm{Nd}$ & 322 & 11 & 362 & 45 & 329 & 51 & 362 & 45 \\
\hline EMAA $-0.5 \mathrm{Nd}$ & 323 & 12 & 360 & 41 & 324 & 43 & 360 & 41 \\
\hline EMAA $-0.6 \mathrm{Nd}$ & 324 & 12 & 359 & 32 & 321 & 31 & 358 & 28 \\
\hline EMAA $-0.8 \mathrm{Nd}$ & 325 & 11 & 357 & 21 & 318 & 21 & 355 & 15 \\
\hline EMAA-1.0Nd & 328 & 11 & 354 & 13 & 315 & 12 & 353 & 7 \\
\hline
\end{tabular}

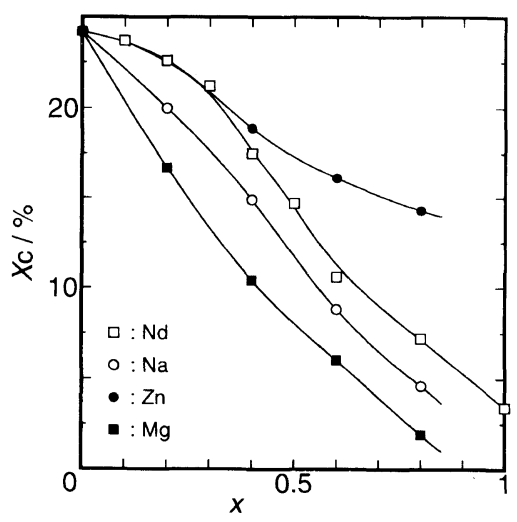

Figure 8. Plots of the degree of crystallinity $\left(X_{\mathrm{c}}\right)$ versus the degree of neutralization $(x)$ for the $\mathrm{Nd}, \mathrm{Na}, \mathrm{Mg}$, and $\mathrm{Zn}$ ionomers.

proposed model, ${ }^{38-40}$ we assign the $T_{\mathrm{i}}$ peak to an order-disorder transition of ionic aggregate regions ${ }^{48}$; the thermal hysteresis appears as a result of a slow reorganization of ionic aggregate regions below $T_{\mathrm{i}}$.

Figure 8 shows plots of the weight fraction of crystallinity $\left(X_{\mathrm{c}}\right)$ versus $x$ for EMAA- $x \mathrm{Nd}$, where the curves for EMAA $-x \mathrm{Na}, \mathrm{EMAA}-x \mathrm{Mg}$, and EMAA $-x \mathrm{Zn}$ are also included. The increase of $x$ decreases the $X_{\mathrm{c}}$ values for these four ionomer systems. This is probably because ionic interactions prevent their crystallization. ${ }^{49}$ The decrease of $\Delta H_{\mathrm{m}}$ with increasing $x$ in EMAA $-x \mathrm{Nd}$ is larger than that in EMAA- $x \mathrm{Zn}$, being comparable to those in EMAA $-x \mathrm{Na}$ and EMAA $-x \mathrm{Mg}$. This result 
suggests that the strength of ionic interactions in EMAA $-x \mathrm{Nd}$ is comparable to those in EMAA $-x \mathrm{Na}$ and EMAA $-x \mathrm{Mg}$. This interpretation is also supported by MFR data which will be discussed later.

\section{Dilatometry}

Figure 9 shows plots of the specific volume $(V)$ versus temperature $(T)$ for EMAA, EMAA- $0.4 \mathrm{Nd}$, and EMAA-0.8Nd. EMAA shows two anomalies near $323 \mathrm{~K}$ and $369 \mathrm{~K}$ in the $V-T$ plot. The latter anomaly is also seen in EMAA- $0.4 \mathrm{Nd}$ and EMAA- $-8.8 \mathrm{Nd}$, and corresponds to the melting of polyethylene crystallites $\left(T_{\mathrm{m}}\right)$. The former anomaly, on the other hand, depends on the degree of neutralization, and is observed near $317 \mathrm{~K}$ for EMAA $-0.4 \mathrm{Nd}$, and as a broad peak near $325 \mathrm{~K}$ for EMAA $-0.8 \mathrm{Nd}$, respectively. From the DSC results mentioned above, the former anomaly near $320 \mathrm{~K}$ is clearly related to the DSC $T_{\mathrm{i}}$ peak. The thermal expansion coefficient, $\alpha$, below $313 \mathrm{~K}$ changed from $7.7 \times 10^{-4}$ for EMAA to $6.9 \times 10^{-4}$ for EMAA- $0.4 \mathrm{Nd}$, and to $5.6 \times 10^{-4} \mathrm{~K}^{-1}$ for EMAA- $0.8 \mathrm{Nd}$. It is considered that the decrease of $\alpha$ with the increase of $x$ may results from the formation of a cross-linked network.

\section{Dynamic Mechanical Results}

Figure 10 shows temperature dependence of dynamic loss modulus $\left(E^{\prime \prime}\right)$ at $10 \mathrm{~Hz}$ for EMAA $-x \mathrm{Nd}$. EMAA shows two relaxations in the temperature range of $123-393 \mathrm{~K}$. Previous investigations ${ }^{21,23,24}$ have shown that the relaxation near $140 \mathrm{~K}$, denoted as $\gamma$, is ascribed to a local molecular motion of the short chain segments and the relaxation at $292 \mathrm{~K}$, denoted as $\beta^{\prime}$, to a microBrownian motion of the long chain segments in the amorphous region. The $E^{\prime \prime}$ curve of EMAA- $-0.3 \mathrm{Nd}$ is similar to that of EMAA, indicating that when $x \leq 0.3$, the $\mathrm{Nd}$ (III) carboxylate side groups are not aggregated. When $x$ reaches 0.5 or higher, the $\beta^{\prime}$ relaxation is replaced by two relaxations at $315-335 \mathrm{~K}$ and near $263 \mathrm{~K}$. The former shifts to higher temperatures with increasing $x$ while the latter stays at almost the same temperature independent of $x$. Such splitting is commonly seen for other EMAA ionomers ${ }^{21,23,24}$; the higher temperature relaxation, usually denoted as $\alpha$, is generally associated with a glass-rubber transition of the ionic cluster phase, and the lower temperature relaxation, denoted as $\beta$, is ascribed to a micro-Brownian motion of the long chain segments in the amorphous polyethylene phase. The appearance of the two relaxations implies that the phase separation between the ionic cluster and polymer matrix phases occurs around $x=0.5$. The $\mathrm{X}$-ray results indicated that the formation of ionic aggregates occurs at $x \geq 0.4$. Therefore, by combining the dynamic mechanical data with the X-ray scattering results, it is concluded that at $\sim 50 \%$ neutralization, the $\mathrm{Nd}(\mathrm{III})$ ionomer begins to form ionic aggregates which, at the same time, construct regions of microphase-separated ionic cluster. This result is contrast to that for other transitionmetal(II) salts of EMAA; for example, the X-ray scattering results ${ }^{42,43}$ indicated that the $\mathrm{Zn}$ (II) salt forms ionic aggregates above $\sim 40 \%$ neutralization, while the dynamic mechanical results ${ }^{24}$ of this salt showed that microphase separation occurs above $80 \%$ neutralization.

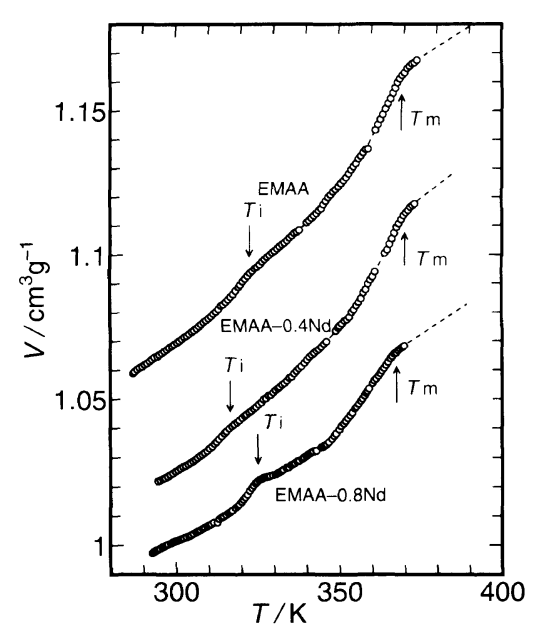

Figure 9. Plots of the specific volume $(V)$ versus temperature $(T)$ for EMAA, EMAA- $0.4 \mathrm{Nd}$, and EMAA- $0.8 \mathrm{Nd}$.

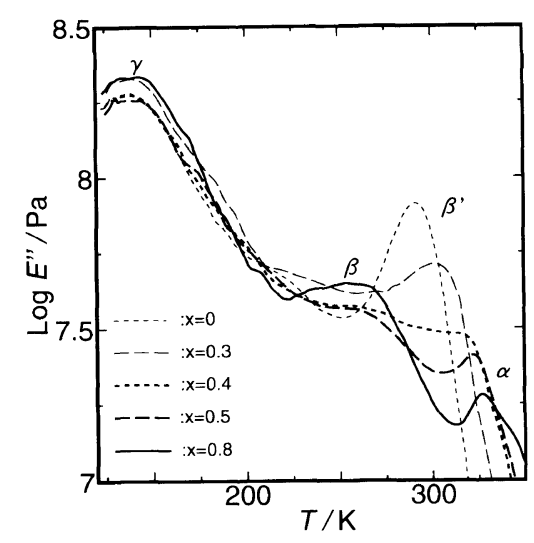

Figure 10. Temperature dependence of the dynamic loss modulus $\left(E^{\prime \prime}\right)$ at $10 \mathrm{~Hz}$ for EMAA- $x \mathrm{Nd}$.

\section{Dielectric Relaxational Results}

Figures 11 and 12 show temperature dependence of dielectric loss $\left(\varepsilon^{\prime \prime}\right)$ at $1 \mathrm{kHz}$ for EMAA $-x \mathrm{Nd}$. The results were essentially identical to those from the dynamic mechanical measurements mentioned above; at $x=0.6$ or higher, the $\beta^{\prime}$ relaxation is replaced into $\alpha$ and $\beta$ relaxations, indicating the formation of ionic cluster phase. In this case, the dielectric $\beta$ relaxation arises primarily from a motion of polar isolated $\mathrm{Nd}$ (III) salt groups dispersed in the amorphous polyethylene phase. In EMAA-0.6Nd and EMAA-0.8Nd, a high ionic conduction occurring above $T_{\mathrm{m}}$ tends to veil the $\alpha$ relaxation at lower frequencies, as seen in Figure 12, but at higher frequencies such as 50 or $100 \mathrm{kHz}$, the $\alpha$ relaxation is clearly visible (see the inset of Figure 12).

Table III summarizes the relaxation parameters of EMAA $-x \mathrm{Nd}$ from both mechanical and dielectric measurements, where the activation enthalpies $(\Delta H)$ were calculated from the Arrhenius plots of the relaxation temperatures versus frequencies. The $\Delta H$ of the mechanical $\beta^{\prime}$ relaxation is almost equal to that of the dielectric $\beta^{\prime}$ relaxation for $x=0$ and 0.1 , but shows a slightly smaller value than the dielectric $\beta^{\prime}$ relaxation for $x=0.2$ and 0.3 . The $\Delta H$ of the $\beta$ relaxation for $x=0.8$ gives a good agreement between the two measurements. For $x=0.4-0.6$, the dielectric $\beta$ relaxation peak was weak and showed a severe overlap with the low tem- 


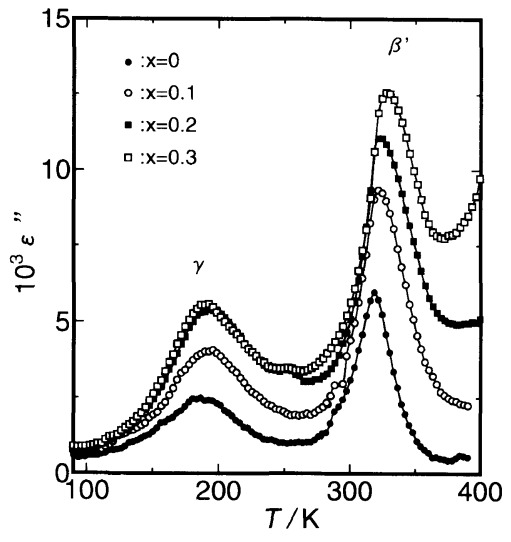

Figure 11. Temperature dependence of the dielectric loss $\left(\varepsilon^{\prime \prime}\right)$ at $1 \mathrm{kHz}$ for EMAA $-x \mathrm{Nd}(x=0-0.3)$.

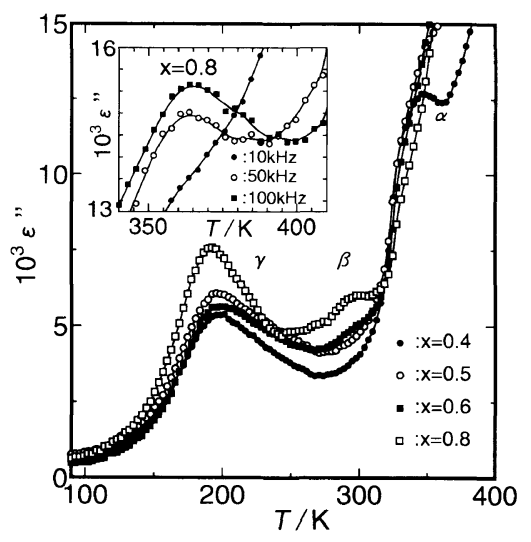

Figure 12. Temperature dependence of the dielectric loss $\left(\varepsilon^{\prime \prime}\right)$ at $1 \mathrm{kHz}$ for EMAA- $-x \mathrm{Nd}(x=0.4-0.8)$. The inset shows the $\varepsilon^{\prime \prime}-T$ curves at higher frequencies for EMAA- $0.8 \mathrm{Nd}$.

Table III. Relaxation parameters of EMAA $-x \mathrm{Nd}$

\begin{tabular}{|c|c|c|c|c|c|c|c|c|c|c|c|c|c|c|}
\hline \multirow{4}{*}{ Sample } & \multicolumn{6}{|c|}{ Mechanical } & \multicolumn{8}{|c|}{ Dielectric } \\
\hline & \multicolumn{2}{|r|}{$\alpha$} & \multicolumn{2}{|r|}{$\beta^{\prime}$} & \multicolumn{2}{|r|}{$\beta$} & \multicolumn{2}{|r|}{$\alpha$} & \multicolumn{2}{|r|}{$\beta^{\prime}$} & \multicolumn{2}{|r|}{$\beta$} & \multicolumn{2}{|r|}{$\gamma$} \\
\hline & $T_{\max } \mathrm{a}$ & $\Delta H$ & $T_{\max }$ & $\Delta H$ & $T_{\max }$ & $\Delta H$ & $T_{\max }{ }^{\mathrm{a}}$ & $\Delta H$ & $T_{\max }$ & $\Delta H$ & $T_{\max }$ & $\Delta H$ & $T_{\max }$ & $\Delta H$ \\
\hline & $\mathrm{K}$ & $\overline{\mathrm{kJ} \mathrm{mol}^{-1}}$ & $\mathrm{~K}$ & $\overline{\mathrm{kJ} \mathrm{mol}^{-1}}$ & $\mathrm{~K}$ & $\overline{\mathrm{kJ} \mathrm{mol}^{-1}}$ & $\mathrm{~K}$ & $\overline{\mathrm{kJ} \mathrm{mol}^{-1}}$ & $\mathrm{~K}$ & $\overline{\mathrm{kJ} \mathrm{mol}^{-1}}$ & K & $\overline{\mathrm{kJ} \mathrm{mol}^{-1}}$ & K & $\mathrm{kJ} \mathrm{mol}^{-1}$ \\
\hline EMAA & & & $292^{\mathrm{b}}$ & $246^{\mathrm{b}}$ & & & & & 318 & $243(5)^{\mathrm{c}}$ & & & 187 & $46(1)$ \\
\hline EMAA $-0.1 \mathrm{Nd}$ & & & 296 & $271(0)$ & & & & & 322 & $270(10)$ & & & 193 & $48(1)$ \\
\hline EMAA $-0.2 \mathrm{Nd}$ & & & 298 & $252(6)$ & & & & & 322 & $290(10)$ & & & 192 & $52(1)$ \\
\hline EMAA $-0.3 \mathrm{Nd}$ & & & 302 & $252(6)$ & & & & & 328 & $330(10)$ & & & 190 & $46(2)$ \\
\hline EMAA $-0.4 \mathrm{Nd}$ & 318 & $420(20)$ & & & $\sim 260$ & $\ldots d$ & 347 & $270(10)$ & & & - & - & 196 & $41(1)$ \\
\hline EMAA $-0.5 \mathrm{Nd}$ & 326 & $380(0)$ & & & 261 & $160(10)$ & 356 & $295(10)$ & & & $\sim 295^{\mathrm{e}}$ & - & 197 & $42(2)$ \\
\hline EMAA $-0.6 \mathrm{Nd}$ & 323 & $420(20)$ & & & 268 & $160(20)$ & $363^{\mathrm{f}}$ & $380(20)$ & & & $\sim 295^{\mathrm{e}}$ & - & 198 & $36(1)$ \\
\hline EMAA $-0.8 \mathrm{Nd}$ & 333 & $340(40)$ & & & 260 & $190(0)$ & $362^{f}$ & $340(20)$ & & & 300 & $197(4)$ & 192 & $50(2)$ \\
\hline EMAA- $-1.0 \mathrm{Nd}$ & 329 & $750(60)$ & & & 263 & $180(0)$ & & & & & & & & \\
\hline
\end{tabular}

${ }^{a}$ Temperatures of the mechanical and dielectric relaxations were measured at $10 \mathrm{~Hz}$ and $1 \mathrm{kHz}$, respectively. $\quad{ }^{\mathrm{b}}$ Taken from ref $24 . \quad{ }^{\mathrm{c}}$ Parentheses indicate the standard deviation from the least-squares fit. ${ }^{\mathrm{d}}$ - , not determined. ${ }^{\mathrm{e}}$ Seen as a shoulder at $300 \mathrm{~Hz}$. ${ }^{\mathrm{f}}$ Extraporated values at $1 \mathrm{kHz}$ in the Arrhenius plots (see the text).

perature side of the $\alpha$ relaxation peak, which makes it difficult to estimate their $\Delta H$ 's accurately. In EMAA$0.6 \mathrm{Nd}$ and EMAA- $-0.8 \mathrm{Nd}$, the $\Delta H$ of the dielectric $\alpha$ relaxation fairly agrees with that of the mechanical $\alpha$ relaxation; the $\Delta H$ 's are between 340 and $420 \mathrm{~kJ} \mathrm{~mol}^{-1}$, and are as large as those of the Na salts of EMAA. ${ }^{26,28}$

In conclusion, the dielectric relaxation studies indicated that the $\mathrm{Nd}$ (III) ionomers form the ionic cluster phase above $\sim 50 \%$ neutralization, being well consistent will the dynamic mechanical results. Here it is noted that the neutralization, at which the ionic cluster phase begin to form, is dependent on the species of metal cation; the neutralization is known to be $\sim 30 \%$ for the $\mathrm{Na}$ ionomer ${ }^{3,21,23-26,28}$ and $\sim 80 \%$ for the $\mathrm{Zn}$ (II) ionomer. $^{24,27}$

Resentry, Eisenberg et al. ${ }^{11}$ proposed an ionic cluster phase model for ionic aggregations; when the ion content increases, the isolated ions begin to form multiplets, which are surrounded with a region restricting the chain mobility. When the ion content increases more, the region of restricted mobility overlaps each other to form an ionic cluster phase which is phase-separated from the polymer matrix. One important point of this model is that the construction of ionic cluster phase does not necessarily accompanied with the formation of larger ionic aggregates. Actually, as already decribed in the $\mathrm{X}$-ray scattering section, the size of ionic aggregation was about $17-20 \AA$, in the $\mathrm{Nd}$ (III) ionomers above $40 \%$ neutralization, comparable to that of $\mathrm{Zn}$ (II) ionomer $(17-19 \AA)$ and somewhat smaller than that of $\mathrm{Na}$ ionomer $(19-27 \AA)$. Moreover the IR $v_{\text {as }}\left(\mathrm{COO}^{-}\right)$ band splitted into the three peaks near 1584, 1541 and $1518 \mathrm{~cm}^{-1}$, where the former two peaks come from the isolated $\mathrm{COO}^{-}$groups and the latter peak, from the $\mathrm{COO}^{-}$group incorporated into the ionic aggregates (see Figure 6). The fraction of $\mathrm{Nd}(\mathrm{III})$ ions incorporated into the ionic aggregates was estimated to be about $25 \%$ at $50 \%$ neutralization, assuming the same absorption coefficient for the three $v_{\text {as }}\left(\mathrm{COO}^{-}\right)$peaks. (This assumption seems to be reasonable, because the sum of the three absorbance intensities was proportional to $x$ in Figure 6.) The ion content in an ionomer neutralized partially by metal cation is estimated as $(p x / n) q$, where $p, x, n$, and $q$ are MAA content in EMAA, degree of neutralization, valence of metal cation, and fraction of ions incorporated into ionic aggregates, respectivly. The ion content was calculated to be about $0.2 \mathrm{~mol} \%$ for the $\mathrm{Nd}(\mathrm{III})$ ionomers at $50 \%$ neutralization, since $p=5.4$ $\operatorname{mol} \%, x=0.5, n=3$, and $q=0.25$. The minimal ion content causing ionic cluster phase separation in the 
$\mathrm{Nd}$ (III) ionomer $(\sim 0.2 \mathrm{~mol} \%)$ is about one-fifth of that in the $\mathrm{Na}$ ionomer $(\sim 1.3 \mathrm{~mol} \%)$ and much less than in the $\mathrm{Zn}(\mathrm{II})$ ionomer $(\sim 2.4 \mathrm{~mol} \%)$.

\section{MFR Data}

Figure 13 shows plots of the melt flow rate (MFR) versus $x$ for EMAA $-x \mathrm{Nd}$. The MFR curves for alkalimetal, alkaline-earth-metal, and transition-metal salts of EMAA are cited from ref 21 . The logarithms of MFR of all the EMAA ionomers decrease almost linearly with increasing $x$. MFR value is usually used as an index of molecular weight of polymers, and in the cross-linked polymers such as ionomers, this value is also affected by the degree of cross-linking. ${ }^{20,21}$ All the EMAA ionomers in Figure 13 were produced from the same starting polymer, EMAA with a specified MFR value of 60. MFR was measured at $463 \mathrm{~K}$ far above $T_{\mathrm{m}}$ and so the polyethylene crystallites, which may act as cross-links at room temperature, were completely melted. Therefore, the MFR value simply reflects the cross-linking effect of the neutralizing cations. Consequently, the observed decrease in MFR with the increase of $x$ suggests the neutralization promotes the formation of ionic aggregates, which act as physical cross-links even in the molten state.

The Nd(III) ionomers show the largest decrease of MFR with neutralization among the EMAA ionomers studied here; the degree of the decrease is in the order of: the $\mathrm{Nd}(\mathrm{III})$ ionomers $>$ the alkaline-earth-metal ionomers $>$ the alkali-metal ionomers $>$ the transitionmetal(II) ionomers. In ionomers, two types of neutralizing cations, (a) isolated ions and (b) aggregated ions, may act as cross-links. The cross-linking effect of aggregated ions is closely connected with the average number of salt groups included in one ionic aggregate. Preliminary X-ray scattering results ${ }^{43}$ showed that the size of the ionic aggregates is largest for the alkali-metal ( $\mathrm{Na})$ ionomers and no marked difference is observed among the transition-metal(II), alkaline-earth-metal, and $\mathrm{Nd}$ (III) ionomers. The cross-linking effect of the alkali-metal salt groups only comes from the ionic aggregation because they are one-connectivity (monovalent) units. On the other hand, the $\mathrm{Nd}$ (III) salt groups should act as three-connectivity units such as $(-\mathrm{COO})_{3} \mathrm{Nd}(\mathrm{III})$, and the salt groups of the alkaline-earth-metal and transition-

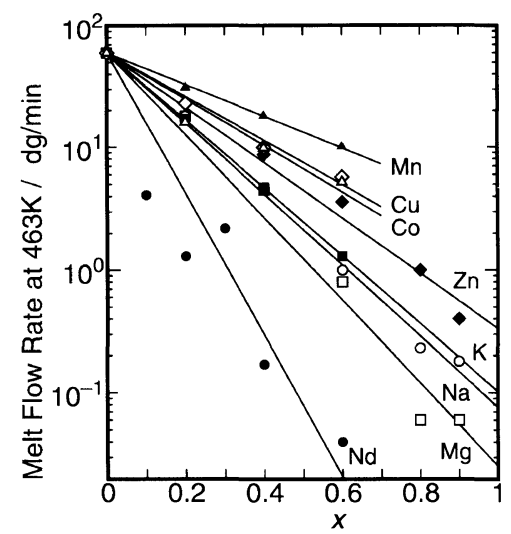

Figure 13. Plots of the melt flow rate versus the degree of neutralization $(x)$ for various types of EMAA ionomers. Cation type: $(\bigcirc) \mathrm{Na}^{+}$; (回) $\mathrm{K}^{+} ;(\square) \mathrm{Mg}^{2+} ;(\Delta) \mathrm{Mn}(\mathrm{II}) ;(\triangle) \mathrm{Co}(\mathrm{II}) ;(\diamond) \mathrm{Cu}(\mathrm{II}) ;(\diamond) \mathrm{Zn}(\mathrm{II})$; (O) $\mathrm{Nd}(\mathrm{III})$. Linear least-squares fits are also shown.
metal(II) ions act as two-connectivity units. Therefore, in the $\mathrm{Nd}(\mathrm{III})$ ionomers, both (a) isolated ions and (b) aggregated ions may act as cross-links. The ionic aggregates in the $\mathrm{Nd}(\mathrm{III})$ ionomers have a similar size to those of the transition-metal(II) and alkaline-earthmetal ionomers, whereas the Nd(III) ionomers show the largest decrease of MFR with increasing $x$ among the EMAA ionomers neutralized by various metal cations. Therefore, the isolated $\mathrm{Nd}(\mathrm{III})$ ions are considered to contribute to the largest decrease of MFR with $x$. This conclusion reveals one feature of the $\mathrm{Nd}$ (III) ionomers that the number of salt groups incorporated into one ionic aggregate is comparatively small, compared with that in the alkali-metal salts, but the density of ionic cross-links formed by both isolated and aggregated ions in the polymer matrix is conversely high. This feature also gives one answer to why the minimal ion content causing the microphase separation is so small in the $\mathrm{Nd}$ (III) ionomers compared with the corresponding values of the $\mathrm{Na}$ and $\mathrm{Zn}$ (II) ionomers.

\section{Stiffness}

Figure 14 shows how the stiffness changes with $x$ for EMAA $-x \mathrm{Nd},-x \mathrm{Na},-x \mathrm{Mg}$, and $-x \mathrm{Zn}$, where the data curves of the latter three ionomer systems are cited from ref 21 . The stiffness curves of all the ionomer systems show a maximum at a degree of neutralization $(x)$, i.e., $\sim 0.5$ for EMAA $-x \mathrm{Nd}$ and $\sim 0.4$ for EMAA $-x \mathrm{Na}$ and $-x \mathrm{Mg}$, and $\sim 0.8$ for EMAA $-x \mathrm{Zn}$, respectively, In the $\mathrm{Na}, \mathrm{Mg}$ and $\mathrm{Zn}$ ionomer systems, these degrees of neutralization were reported to correspond with the minimal degrees of neutralization causing microphase separation of ionic aggregates from the polymer matrix. $^{21,24}$ Apparently, this result holds in the $\mathrm{Nd}(\mathrm{III})$ ionomer system; the dynamic mechanical and dielectric relaxational results indicated that the microphase separation of ionic aggregates begins to occur near $x=0.5$ in the $\mathrm{Nd}$ (III) ionomer system. The stiffness data also show that the $\mathrm{Nd}$ (III) ionomer system exhibit the largest maximum value among the four ionomer systems, which reflects the densely cross-linked structure of this ionomer system, as described above. Table IV summarizes a few mechanical properties of the $\mathrm{Nd}$ (III) ionomers. The $\mathrm{Nd}$ (III) ionomers show no marked difference in tensile strength and elongation at break, compared with other EMAA ionomers. ${ }^{21}$

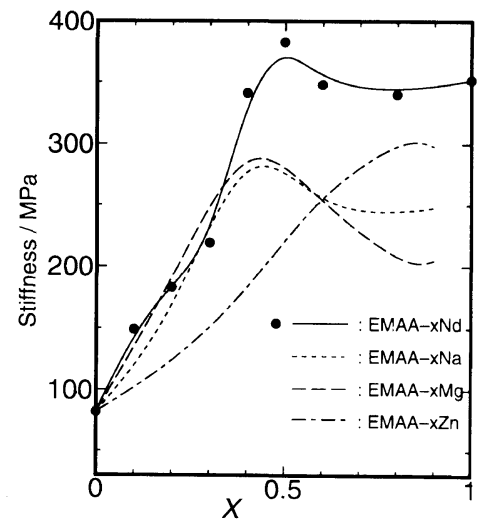

Figure 14. Plots of the stiffness versus the degree of neutralization $(x)$ for EMAA $-x \mathrm{Nd}$, EMAA $-x \mathrm{Na}$, EMAA $-x \mathrm{Mg}$, and EMAA $-x \mathrm{Zn}$. 
Table IV. Mechanical data of EMAA $-x \mathrm{Nd}$

\begin{tabular}{|c|c|c|c|}
\hline \multirow{4}{*}{ Sample } & \multirow{4}{*}{$\begin{array}{c}\text { Stiffness } \\
\text { MPa }\end{array}$} & \multicolumn{2}{|c|}{ Tensile properties } \\
\hline & & \multirow{2}{*}{$\begin{array}{l}\text { Tensile } \\
\text { strength }\end{array}$} & \multirow{2}{*}{$\begin{array}{c}\text { Elongation } \\
\text { at break }\end{array}$} \\
\hline & & & \\
\hline & & $\mathrm{MPa}$ & $\%$ \\
\hline EMAA & 47 & 24 & 542 \\
\hline EMAA $-0.1 \mathrm{Nd}$ & 149 & 19 & 370 \\
\hline $\mathrm{EMAA}-0.2 \mathrm{Nd}$ & 183 & 20 & 300 \\
\hline EMAA $-0.3 \mathrm{Nd}$ & 219 & 26 & 372 \\
\hline EMAA $-0.4 \mathrm{Nd}$ & 341 & 28 & 340 \\
\hline EMAA- $-0.5 \mathrm{Nd}$ & 383 & 28 & 244 \\
\hline EMAA $-0.6 \mathrm{Nd}$ & 348 & 27 & 212 \\
\hline EMAA $-0.8 \mathrm{Nd}$ & 340 & 27 & 120 \\
\hline $\mathrm{EMAA}-1.0 \mathrm{Nd}$ & 352 & 23 & 40 \\
\hline EMAA $-0.6 \mathrm{Na}^{\mathrm{a}}$ & 256 & 32 & 295 \\
\hline EMAA $-0.6 \mathrm{Mg}^{\mathrm{a}}$ & 254 & 29 & 299 \\
\hline EMAA $-0.6 \mathrm{Zn}^{\mathrm{a}}$ & 255 & 28 & 375 \\
\hline
\end{tabular}

a Taken from ref 21 .

\section{CONCLUSIONS}

The Nd(III) salts of EMAA with various degrees of neutralization were synthesized as the first examples of well-characterized EMAA ionomers containing a trivalent neutralizing cation, and the structure and physicochemical properties were studied for these materials. The X-ray scattering patterns showed an ionomer peak near $2 \theta=5^{\circ}$, when $x \geq 0.4$, and the increase of $x$ decreased the degree of crystallinity of polyethylene segments. In the visible spectra, there was observed a broad absorption peak near $585 \mathrm{~nm}$ which are assigned to ${ }^{4} \mathrm{I}_{9 / 2} \rightarrow{ }^{4} \mathrm{G}_{5 / 2},{ }^{4} \mathrm{G}_{7 / 2}$ transition for the octahedral coordinated $\mathrm{Nd}$ (III) ions. The plot of absorption intensity versus $x$ bent near $x=0.5$ and this bend indicated the existence of $\mathrm{Nd}(\mathrm{III})-\mathrm{Nd}$ (III) interactions at $x \geq$ 0.5 . The IR results suggested that local environments around $\mathrm{Nd}(\mathrm{III})$ ions significantly change at $x \sim 0.5$ : The $1698-\mathrm{cm}^{-1}$ peak, assigned to the hydrogen-bonded carbonyl stretching vibration, monotonously decreased with increasing $x$, while the $1669-\mathrm{cm}^{-1}$ peak, assigned to the stretching vibration of the hydrogen-bonded carbonyl groups weakly coordinated to the $\mathrm{Nd}(\mathrm{III})$ carboxylates, increased with increasing $x$ from 0 to 0.5 but decreased above $x=0.5$. The $\mathrm{COO}^{-}$asymmetric stretching bands $\left(v_{\text {as }}\left(\mathrm{COO}^{-}\right)\right)$were observed near 1584 and $1541 \mathrm{~cm}^{-1}$, and these intensities initially increased with increasing $x$ but reversely decreased above $x=0.5$. On the other hand, another peak appeared near 1518 $\mathrm{cm}^{-1}$ around $x=0.4$ and steeply increased with increasing $x$ above $x=0.5$. The $1518-\mathrm{cm}^{-1}$ peak was assigned to the asymmetric stretching vibration of $\mathrm{COO}^{-}$coordinated to aggregated $\mathrm{Nd}(\mathrm{III})$ ions. The IR spectral result suggests that when $x \geq 0.5$ a part of $\mathrm{Nd}$ (III) ions is incorporated in the ionic aggregates. From the present X-ray scattering, visible and IR spectral studies, it was concluded that ionic aggregation begins to occur near $x=0.5$ for the $\mathrm{Nd}($ III) salts of EMAA.

In dynamic mechanical and dielectric relaxational results, the $\beta^{\prime}$ relaxation, assigned to a micro-Brownian molecular motion of long chain segments, was replaced by $\alpha$ and $\beta$ relaxations, which were assigned, respectively, to a glass-rubber transition of the ionic cluster phase and a micro-Brownian molecular motion of long chain segments in the amorphous polyethylene phase. Therefore, we concluded that a microphase separation of ionic aggregates from the polymer matrix, i.e., the formation of ionic cluster phase, occurs above $x \sim 0.5$. The activation energy for the $\alpha$ relaxation is large $(340-420$ $\mathrm{kJ} \mathrm{mol}^{-1}$ ), which suggests that the backbone chain segments incorporated into the ionic cluster phase are densely cross-linked and largely entangled, and thus their segmental mobility is significantly reduced. This picture supports Eisenberg's new cluster model. ${ }^{11}$ The minimal ion content causing the microphase separation was roughly estimated to be $0.2 \mathrm{~mol} \%$, being only about one-fifth of the case of the Na ionomers. The MFR data also support the formation of a densely cross-linked network, especially above $x \sim 0.5$. The highly cross linked $\mathrm{Nd}(\mathrm{III})$ ionomers provided the highest stiffness maximum among the EMAA ionomer systems neutralized with various metal cations.

In conclusion, the $\mathrm{Nd}(\mathrm{III})$ salts of EMAA start associating near $50 \%$ neutralization to form ionic aggregates, and almost simultaneously with the ionic aggregation, noteworthily, a microphase separation of ionic aggregates from the polymer matrix begins to occur and construct an ionic cluster phase. As a result, the structure becomes a densely cross-linked state.

Acknowledgements. We greatly thank Professor Kenji Tadano of Gifu College of Medical Technology for his assistance of dielectric and dilatometric measurements. We also thank Dr. Eisaku Hirasawa and $\mathrm{Mr}$. Yoshikazu Kutsuwa of Du Pont-Mitsui Polychemicals Co., Ltd., and Professor Jun Yamauchi of Kyoto University for their valuable discussions. We thank the Instrument Center, Institute for Molecular Science for assistance in obtaining the X-ray data. This work was partly supported by a Grant-in-Aid for Scientific Research (No. 05555254, 07650797) from the Ministry of Education, Science, and Culture of Japan.

\section{REFERENCES AND NOTES}

1. R. W. Rees and D. J. Vaughan, Polym. Prepr. (Am. Chem. Soc., Div. Polym. Chem.), 6, 287 (1965).

2. R. W. Rees and D. J. Vaughan, Polym. Prepr. (Am. Chem. Soc., Div. Polym. Chem.), 6, 296 (1965)

3. L. Holliday, Ed., "Ionic Polymers," Applied Sciences, London, 1975.

4. A. Eisenberg and M. King, "Ion-Containing Polymers: Physical Properties and Structure," Polymer Physics Vol. 2, Academic Press, New York, N. Y., 1977.

5. M. Pineri and A. Eisenberg, Ed., "Structure and Properties of Ionomers," NATO ASI Series C: Mathematical and Physical Sciences Vol. 198, D. Reidel Co., Dordrecht, The Netherland, 1987.

6. L. A. Utracki and R. A. Weiss, Ed., "Multiphase Polymers: Blends and Ionomers," ACS Symposium Series 395, American Chemical Society, Washington, D.C., 1989.

7. A. Eisenberg, Macromolecules, 3, 147 (1970)

8. W. J. MacKnight, W. P. Taggart, and R. S. Stein, J. Polym. Sci., Polym. Symp., 45, 113 (1974).

9. A. Moudden, A. M. Levelut, and M. Pineri, J. Polym. Sci., Polym. Phys. Ed., 15, 1707 (1977).

10. D. J. Yarusso and S. L. Cooper, Macromolecules, 16, 1871 (1983).

11. A. Eisenberg, B. Hird, and R. B. Moore, Macromolecules, 23, 4098 (1990) 
12. J. A. Lefelar and R. A. Weiss, Macromolecules, 17, 1145 (1984)

13. Y. S. Ding, R. A. Register, C. Yang, and S. L. Cooper, Polymer, 30, 1204 (1989)

14. Y. S. Ding, R. A. Register, C. Yang, and S. L. Cooper, Polymer, 30, 1213 (1989)

15. Y. S. Ding, R. A. Register, C. Yang, and S. L. Cooper, Polymer, 30, 1221 (1989).

16. M. R. Tant, J. H. Song, G. L. Wilkes, J. Horrion, and R. Jérôme, Polymer, 27, 1815 (1986).

17. M. R. Tant, L. N. M. Venkateshwaran, J. H. Song, R. Subramanian, G. L. Wilkes, P. Charlier, and R. Jérôme, Polymer, 33, 1347 (1992).

18. R. A. Register, M. Foucart, R. Jérôme, Y. S. Ding, and S. L. Cooper, Macromolecules, 21, 1009 (1988).

19. S. Yang, K. Sun, and W. M. Risen, Jr., J. Polym. Sci., Polym. Phys., 28, 1685 (1990).

20. S. Bonotto and E. F. Bonner, Macromolecules, 1, 510 (1968).

21. E. Hirasawa, Y. Yamamoto, K. Tadano, and S. Yano, J. Appl. Polym. Sci., 42, 351 (1991)

22. H. Tachino, H. Hara, E. Hirasawa, S. Kutsumizu, and S. Yano, Macromolecules, 27, 372 (1994)

23. W. J. MacKnight, L. W. McKenna, and B. E. Read, J. Appl. Phys., 38, 4208 (1967).

24. H. Tachino, H. Hara, E. Hirasawa, S. Kutsumizu, K. Tadano, and S. Yano, Macromolecules, 26, 752 (1993).

25. B. E. Read, E. A. Carter, T. M. Connor, and W. J. MacKnight, Br. Polym. J., 1, 123 (1969).

26. P. J. Phillips and W. J. MacKnight, J. Polym. Sci., Polym. Phys. Ed., 8, 727 (1970).

27. S. Yano, H. Yamamoto, K. Tadano, Y. Yamamoto, and E. Hirasawa, Polymer, 28, 1965 (1987).

28. S. Yano, N. Nagao, M. Hattori, E. Hirasawa, and K. Tadano, Macromolecules, 25, 368 (1992).

29. H. W. Straus, U. S. Patent 4716202 (1987).

30. Y. Li, G. Liu, and G. Yu, J. Macromol. Sci.-Chem., A26, 405 (1989)
31. G. Yu, Y. Li, Y. Qu, and X. Li, Macromolecules, 42, 6702 (1993).

32. E. Hirasawa, H. Hamazaki, K. Tadano, and S. Yano, J. Appl. Polym. Sci., 42, 621 (1991).

33. Abstracts of Papers, International Symposium on OrganoMettallic Chemistry and Catalysis, Hohhot, China, August, 1994, p. 17.

34. E. Hirasawa, K. Tadano, and S. Yano, J. Polym. Sci., Polym. Phys. Ed., 29, 753 (1991).

35. J. J. Fitzgerald, D. Kim, and R. A. Weiss, J. Polym. Sci., Polym. Lett., 24, 263 (1986).

36. S. Kutsumizu, N. Nagano, K. Tadano, H. Tachino, E. Hirasawa, and S. Yano, Macromolecules, 25, 6829 (1992).

37. H. Tachino, H. Hara, E. Hirasawa, S. Kutsumizu, and S. Yano, J. Appl. Polym. Sci., 55, 131 (1995).

38. K. Tadano, E. Hirasawa, Y. Yamamoto, H. Yamamoto, and S. Yano, Jpn. J. Appl. Phys., 26, L1440 (1987).

39. K. Tadano, E. Hirasawa, H. Yamamoto, and S. Yano, Macromolecules, 22, 226 (1989).

40. E. Hirasawa, Y. Yamamoto, K. Tadano, and S. Yano, Macromolecules, 22, 2776 (1989).

41. N. Koizumi and S. Yano, Bull. Inst. Chem. Res., Kyoto Univ., 47, 320 (1969).

42. D. J. Yarusso and S. L. Cooper, Polymer, 26, 371 (1985)

43. S. Kutsumizu, unpublished results.

44. R. B. Moore, D. Bittencourt, M. Gauthier, C. E. Williams, and A. Eisenberg, Macromolecules, 24, 1376 (1991).

45. D. G. Karraker, J. Inorg. Nucl. Chem., 31, 2815 (1969).

46. K. Han and H. L. Williams, J. Appl. Polym. Sci., 38, 73 (1989).

47. K. Nakamoto, "Infrared and Raman Spectra of Inorganic and Coordination Compounds," 3rd ed, John Wiley \& Sons, New York, N. Y., 1978

48. In EMAA, some weakly ordered strucuture would be formed via hydrogen bonding of carboxylic acid groups.

49. Y. Tsujita, K. Shibayama, A. Takizawa, T. Kinoshita, and I. Uematsu, J. Appl. Polym. Sci., 33, 1307 (1987).

50. K. Tadano, unpublished results. 